$$
\text { NASA TN } 86976
$$

NASA Technical Memorandum 86976

\title{
Alloys Based on NiAl for High Temperature Applications
}

K. Vedula, V. Pathare and I. Aslanidis

Case Western Reserve University

Cleveland, Ohio

and

R.H. Titran

Lewis Research Center

Cleveland, Ohio

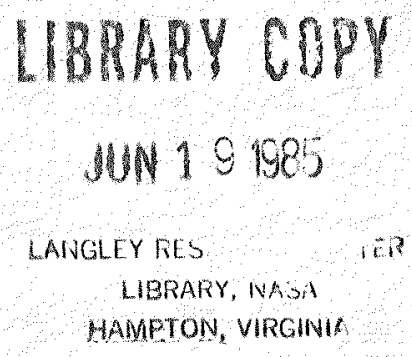

Prepared for the

1984 Fall Meeting of the Materials Research Society

Boston, Massachusetts, November 26-30, 1984

\section{N/SA}


K. VEDULA*, V. PATHARE*, I. ASLANIDIS* and R. H. TITRAN**

* Department of Metallurgy and Materials Science, Case Western Reserve University, Cleveland, Ohio;** NASA Lewis Research Center, Cleveland, Ohio

\section{ABSTRACT}

This paper presents some of the results obtained in an on-going study of NiAT alloys for potential high temperature applications. Alloys were prepared by powder metallurgy techniques. Flow stress values at slow strain rates and high temperatures were measured. Some promising ternary alloying additions ( $\mathrm{Hf}, \mathrm{Ta}$ and $\mathrm{Nb}$ ) have been identified. The mechanism of strengthening in alloys containing these additions appears to be a form of particle dislocation interaction. Interesting effects of grain size and stoichiometry in binary alloys are also presented.

\section{INTRODUCTION}

NiAl is one of the interesting intermetallic compounds for potential use as a high-temperature structural material. The ordered structure is believed to provide high-temperature strength and the aluminum content provides the oxidation resistance. This paper presents some of the results of a broader study on the potential for NiAl and FeAl based alloys for high-temperature applications.

Stoichiometric NiAl has an ordered L20 (B2) crystal structure up to its congruent melting point of $1911^{\circ} \mathrm{K}\left(1638^{\circ} \mathrm{C}\right)$. Figure 1 shows the binary $\mathrm{A} 1-\mathrm{Ni}$ phase diagram [1]. The ordered $\mathrm{B} 2$ structure is maintained over the composition range from 45.0 to 58.5 at \% at room temperature. This provides the potential for improving high temperature strength by solid solution alloying. However, very limited information on the alloying behavior of NiAl is available. A previous publication by these authors [2] contains some information on the potential for solid solubility of several ternary additions. Ti, $\mathrm{Mn}, \mathrm{Cr}, \mathrm{Fe}$ and $\mathrm{Cu}$ are found to have considerable solubilities in binary $\mathrm{NiAl}$, whereas $\mathrm{Nb}, \mathrm{Hf}, \mathrm{Ta}, \mathrm{Mo}, \mathrm{W}$ and $\mathrm{Zr}$ are found to have very limited solubilities.

Deviations from stoichiometry on either side are accomodated by defect structures $[3,4]$. The defects on the nickel-rich side are believed to be antistructure defects (with excess nickel atoms occupying aluminum sites) and those on the aluminum-rich side are believed to be vacancies (with the nickel deficient sites remaining vacant). There is, however, some indication that even the stoichiometric alloy may contain a combination of both these types of defects and that the aluminum rich structure may contain a complex triple defect structure. Hence, within the single phase field of the ordered structure, mechanical properties are sensitive to deviations from stoichiometry [5]. At low temperatures, deviations from stoichiometry result in defect hardening. On the other hand, at high temperatures defects are believed to increase the diffusion processes and hence weaken the alloys.

Previous investigations of B2 aluminides have shown some peculiar grain size effects $[6,7,8]$, in which fine grained material is observed to be stronger than coarse grained material even at temperatures 


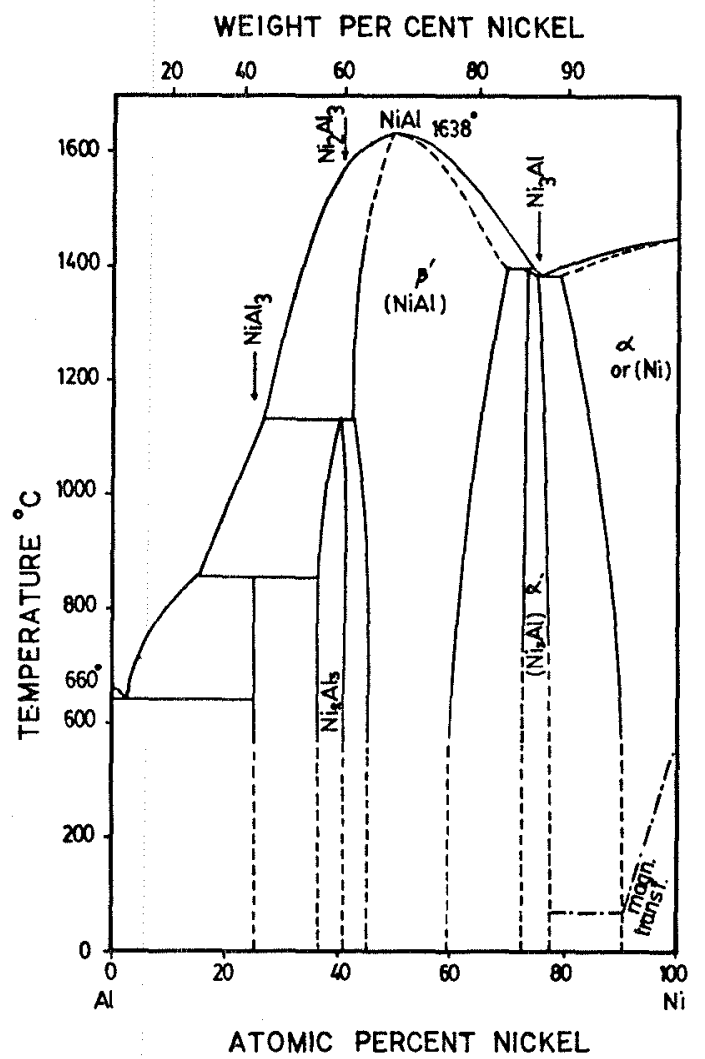

Fig. 1. Binary AT-Ni Phase Diagram [1]

of the order of $0.7 \mathrm{Tm}$. In particular, this effect has been noted for extruded FeAl alloys [6]. The reasons for this behavior are unknown and must be related to the effects of ordering on grain boundary structure and high temperature deformation mechanisms.

This paper discusses some of the observations of potential strengthening mechanisms in NiAl based alloys. These observations form part of an overall program at NASA Lewis Research Center to develop NiAl alloys for high temperature applications. In particular, the effects of ternary additions, grain size and deviations from stoichiometry will be discussed.

\section{MATERIALS AND PROCEDURE}

Powder metallurgy processing was found to be a convenient method for processing these alloys.

Ternary alloys were prepared from blends of prealloyed NiAl and elemental ternary additions. Consolidation was achieved by either hot extrusion or hot isostatic pressing of canned powder. Alloys were heat treated after consolidation in order to ensure maximum homogeneity. Grain sizes of these ternary alloys were typically in the range of 25 to $50 \mu \mathrm{m}$. Specific details of the processing with ternary additions are presented elsewhere [2]. Compositions of alloys reported in the previous publications are presented in Table I. New alloys containing 2 at $\% \mathrm{Ti}$, Ta and $\mathrm{Nb}$ were later prepared and are discussed in this paper. Compositions of these alloys are presented in Table II. 
TABLE I. Gross Chemical Composition of Alloys From Reference 2 (Atomic \%)

\begin{tabular}{l|cccc} 
Specimen & $\mathrm{Ni}$ & $\mathrm{Al}$ & Ternary & $\mathrm{Fe}^{1}$ \\
\hline HIPPED ALLOYS & & & & \\
NiA1 & 55.28 & 44.60 & -- & 0.001 \\
NiA1-Ti & 49.89 & 47.18 & $2.16 \mathrm{Ti}$ & 0.330 \\
NiA1-Ta & 51.12 & 46.39 & $1.17 \mathrm{Ta}$ & 1.310 \\
NiA1-Nb & 49.12 & 46.28 & $1.00 \mathrm{Nb}$ & 3.630 \\
NiA1-Mn & 50.03 & 47.22 & $2.52 \mathrm{Mn}$ & 0.002 \\
NiA1-Mo & 49.70 & 47.18 & $2.92 \mathrm{Mo}$ & 0.002
\end{tabular}

HOT EXTRUDED ALLOYS

\begin{tabular}{l|lll} 
NiA1-Fe & 45.19 & 49.54 & $5.27 \mathrm{Fe}$ \\
NiA1-Mo & 41.84 & 53.73 & $4.43 \mathrm{Mo}$ \\
NiA1-W & 41.87 & 53.63 & $4.50 \mathrm{~W}$ \\
NiA1-Re & 41.98 & 53.59 & $4.42 \mathrm{Re}$ \\
NiA1-Mn2 & 53.00 & 42.00 & $5.00 \mathrm{Mn}$ \\
NiA1-Hf & 45.32 & 53.63 & $1.05 \mathrm{Hf}$
\end{tabular}

7 Impurity

2 Intended Composition

TABLE II. Intended Gross Chemical Compositions of Second Alloy Series (Atomic \%)

Specimen $\quad \mathrm{Ni} \quad \mathrm{Al}$ Ternary

\begin{tabular}{l|lll}
\hline NTi2 & 50.00 & 48.00 & $2.00 \mathrm{Ti}$ \\
NNb2 & 50.00 & 48.00 & $2.00 \mathrm{Nb}$ \\
NTa2 & 50.00 & 48.00 & $2.00 \mathrm{Ta}$ \\
\hline
\end{tabular}

Fine grain sizes $(<\operatorname{than} 10 \mu \mathrm{m})$ were obtained in the binary alloys by reextruding at a lower temperature $\left(1073^{\circ} \mathrm{K}\right)$ after initial extrusion at a higher temperature $\left(1350^{\circ} \mathrm{K}\right)$. This was carried out for binary alloys having compositions of 48 at\% $\mathrm{Ni}, 50$ at\% $\mathrm{Ni}$ and 52 at\% $\mathrm{Ni}$. Coarse grains were obtained by annealing extruded specimens in argon for varying lengths of time up to 144 hours at $1625^{\circ} \mathrm{K}$ and $1723^{\circ} \mathrm{K}$. Deviations from stoichiometry were obtained by using different compositions of prealloyed powders.

Microstructures of alloys were observed using optical and electron microscopy.

High temperature testing was accomplished using constant strain rate compression testing of small cylindrical specimens (approximately $5 \mathrm{~mm}$ by $10 \mathrm{~mm}$ ) on an Instron machine in air at temperatures ranging from $1100^{\circ} \mathrm{K}$ to $1400^{\circ} \mathrm{K}$. Specimens were normally tested to about $10 \%$ reduction in heights and flow stress was recorded. Load - deformation information was converted to true stress - true strain information neglecting the slight barreling of the specimens. Flow stress remained 
fairly constant during the plastic deformation. Values of the maximum flow stress and corresponding strain rate were used to compare the high temperature behavior of various specimens.

\section{RESULTS AND DISCUSSION}

The results will be discussed in the light of potential strengthening mechanisms resulting from: (a) alloying additions, (b) grain boundaries and (c) deviations from stoichiometry.

\section{(A) Alloying Additions}

The alloying additions used could be classified on the basis of microstructural evaluation [2]. Extent of homogeneity in the specimens was evaluated by EDAX analyses. The alloys containing $\mathrm{Ti}, \mathrm{Mn}$ and $\mathrm{Fe}$ were essentially shown to be homogeneous single phase alloys with no evidence of undissolved ternary powders. Alloys containing $\mathrm{Ta}, \mathrm{Nb}, \mathrm{Hf}$ and Re showed a significant amount of undissolved ternary powder in spite of a certain amount of dissolution and alloys containing Mo and $W$ showed a negligible amount of dissolution.

The alloying additions which have poor solubility in the matrix, in general, appear to provide more strengthening at high temperatures than those with large solubilities. This trend was clearly indicated in the results presented previously and reproduced in Figure 2 [2]. Compositions of the alloys shown in this figure are tabulated in Table I. The alloys containing $\mathrm{Ti}, \mathrm{Mn}$ and $\mathrm{Fe}$ did not show any significant improvements over binary alloys in compressive creep tests conducted in air at $1300^{\circ} \mathrm{K}$. These are single phase alloys and the small amount of strengthening observed is probably due to solid solution effects. The alloys containing $\mathrm{Ta}$, $\mathrm{Nb}$ and $\mathrm{Hf}$ exhibited very substantial strengthening compared to the binary alloys. These alloying additions only dissolved to a very small extent in the matrix NiAl, as indicated by the presence of undissolved ternary additions even after very long homogenization treatments.

This same trend is observed in the second series of alloys (NTi2, NNb2, NTa2) tested in hot compression at $1300^{\circ} \mathrm{K}$. Figure 3 compares these alloys with binary data obtained from [2]. Compositions of this series of alloys are given in Table II. The alloys containing $\mathrm{Ta}$ and $\mathrm{Nb}$ are much stronger than the binary alloy and the alloy containing $\mathrm{Ti}$.

The strength of the stronger alloys ( $\mathrm{Ta}$ and $\mathrm{Nb}$ containing alloys) appears to be more temperature dependent than that of the binary alloys. This is illustrated in Figure 4 which shows that although the $\mathrm{Ta}$ alloy is significantly stronger (about twice as strong at constant strain rate) than the binary at $1400^{\circ} \mathrm{K}$, its superiority over the binary alloy is much more at $1200^{\circ} \mathrm{K}$ (about ten times as strong at constant strain rate). This difference in temperature dependence suggests that whatever the actual mechanism of high temperature deformation in these alloys, the activation energy for the mechanism increases with the alloying addition. 


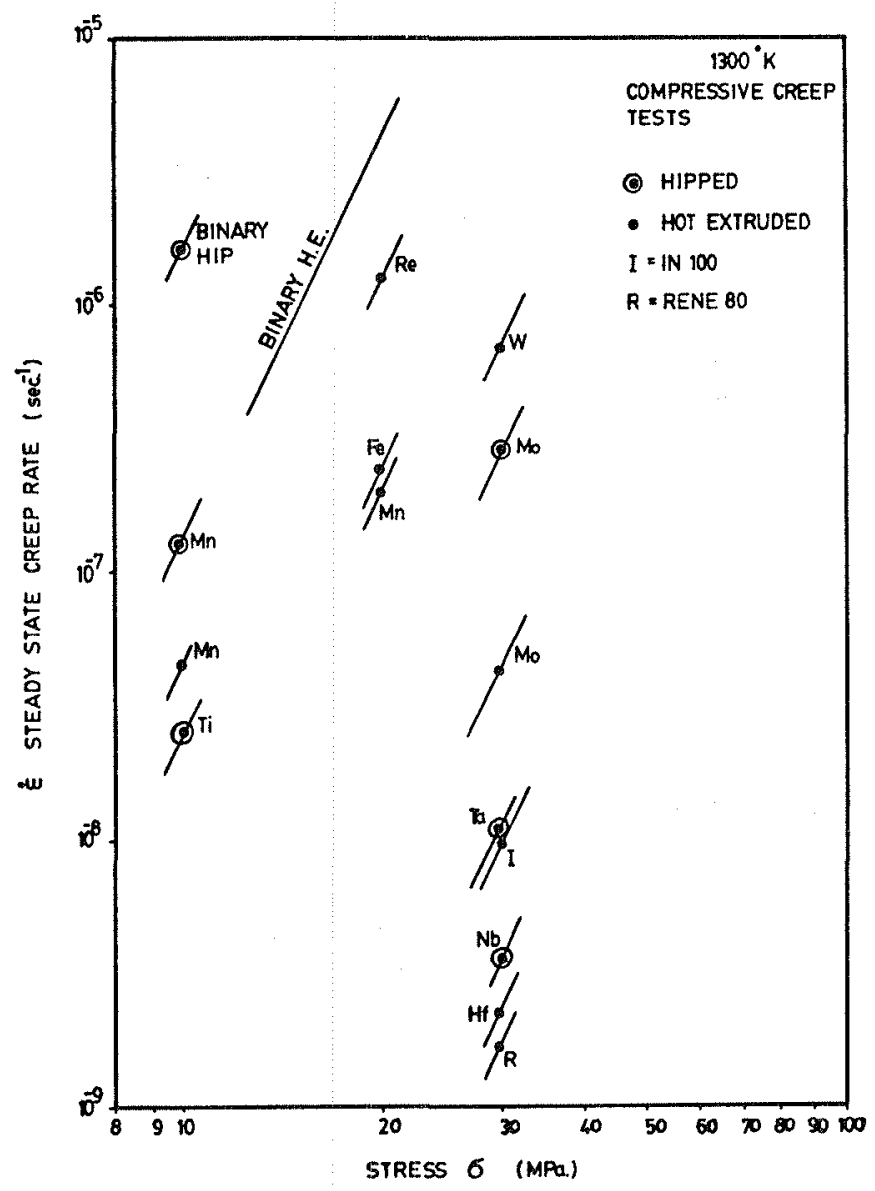

Fig. 2. Comparison of Compressive Creep Behavior of Several Ternary NiAT Alloys and Conventional Superalloys at $1300^{\circ} \mathrm{K}$ [2]. The ternary alloying addition is indicated at the data point.

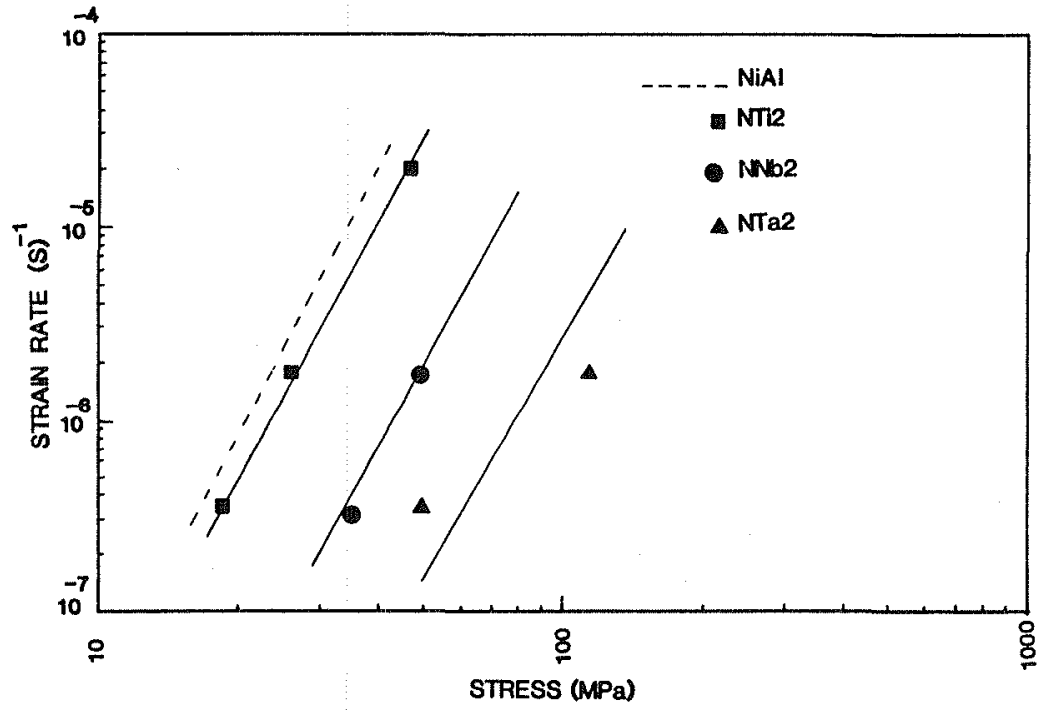

Fig. 3.

Comparison of $1300^{\circ} \mathrm{K}$ Hot Compressive Flow Stress Behavior for additions of $\mathrm{Ti}, \mathrm{Ta}$ and $\mathrm{Nb}$ at 2 at\% level. 


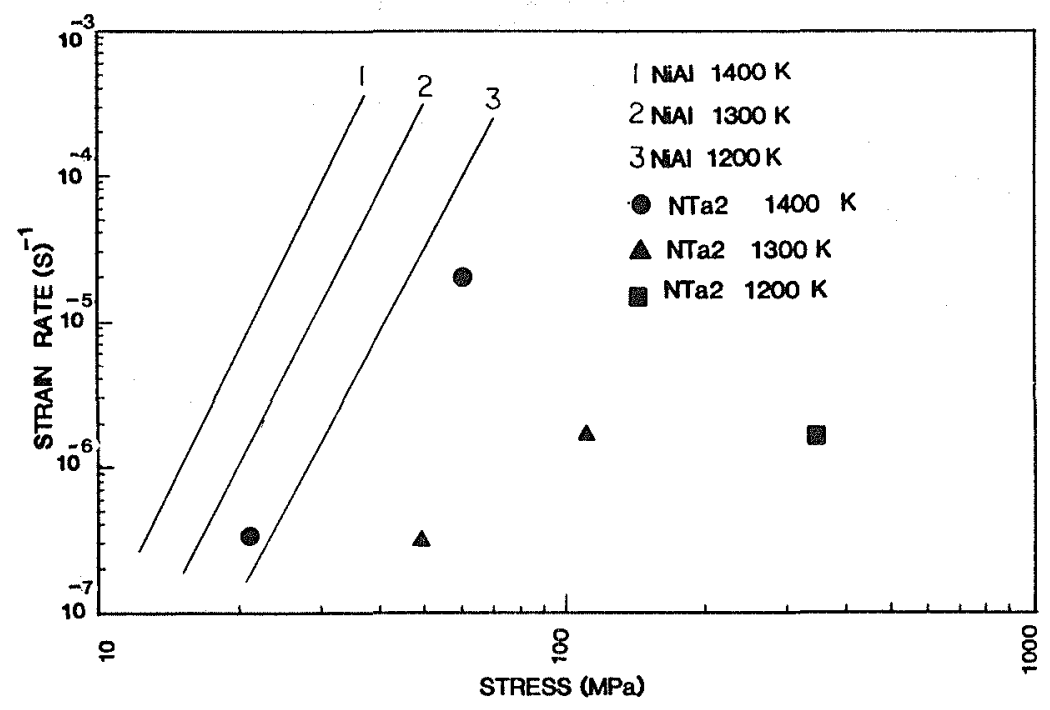

Fig. 4. Comparison of Hot Compresssive Flow Stress Behavior of Binary Stoichiometric NiAT [8] with $\mathrm{Ni}(50$ at\%)A1 (48 at\%)-Ta(2 at\%) at three temperatures.

The mechanism of strengthening for the alloys containing $\mathrm{Ta}$ and $\mathrm{Nb}$ appears to be some form of interaction between dislocations and fine precipitates which are richer in the alloying addition. This is indicated quite strongly by the TEM microstructure of the deformed Ta-containing alloy illustrated in Figure 5 . Typical bowing of dislocations between sub-micron sized particles is obvious. These particles are found to be rich in $\mathrm{Ta}$ and are probably a ternary intermetallic of $\mathrm{Ni}, \mathrm{Ta}$ and $\mathrm{Al}$. These fine precipitates appear to have formed during the slow cooling of the specimen after homogenization treatment, since homogenization in these alloys does result in a certain amount of dissolution of the ternary addition and since the solubility of this ternary element is expected to decrease at lower temperatures. A more detailed TEM investigation is needed in order to clearly understand the nature, the mechanism of formation and role of these precipitates.

\section{(B) Grain Size and Stoichiometry}

A wide range of grain sizes have been obtained using the technique of a second extrusion at a lower temperature. Typical grain sizes obtained by reextrusion followed by annealing are illustrated in Figure 6. (Note the factor of 20 difference in magnifications). Grain sizes obtained for the three alloys studied under different annealing conditions are presented in Table III.

An interesting aspect of the grain growth of these alloys appears to be that it is slow in the beginning but becomes much more rapid after some time resulting in a deviation from the standard power law grain growth kinetics. Figure 7 for grain growth at $1723^{\circ} \mathrm{K}$ illustrates this type of behavior. This appears to be indicative of some form of abnormal grain growth and, in fact, optical microstructures do reveal a bimodal distribution of grains in the coarse grained specimens. 


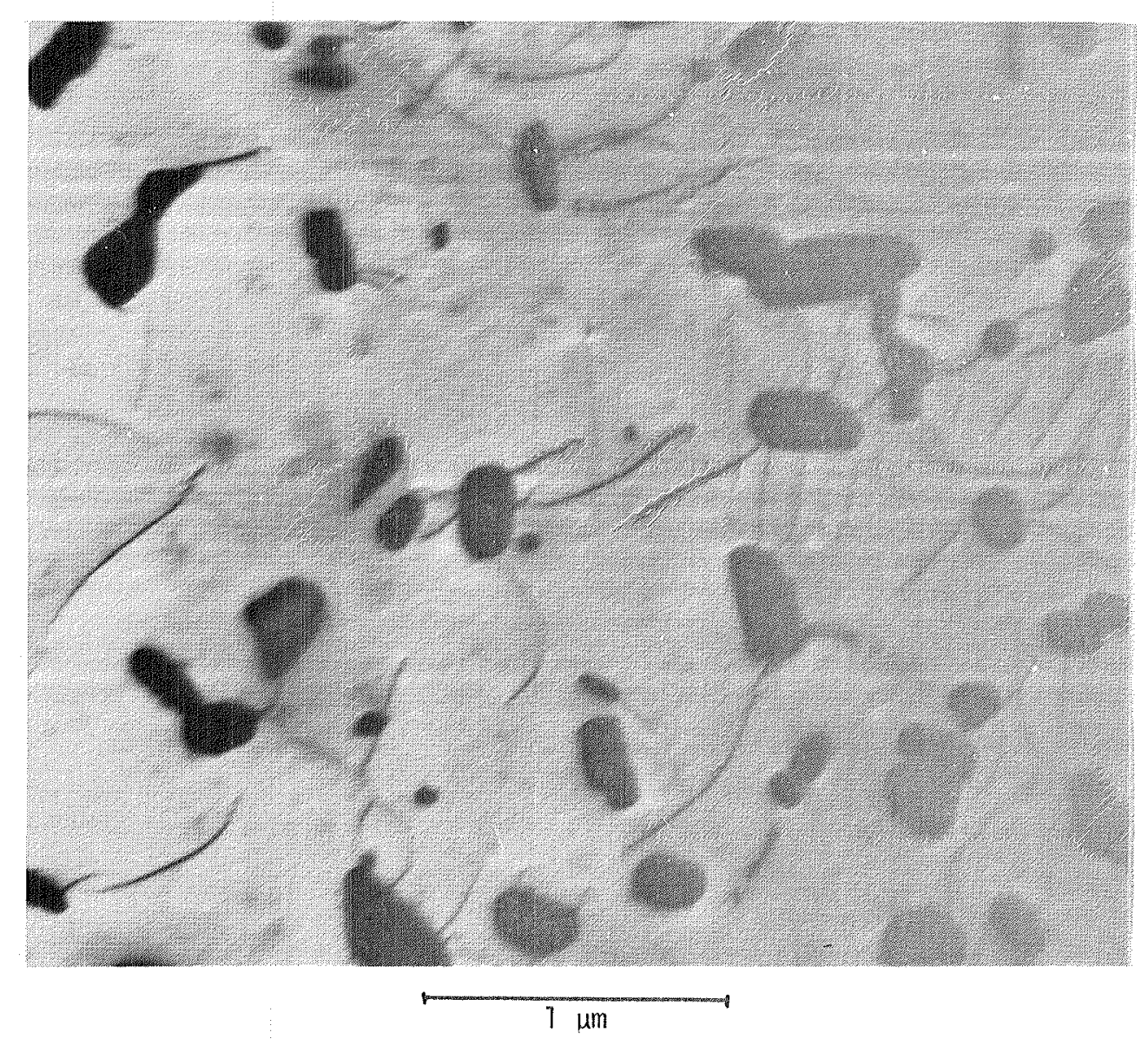

Fig. 5. Transmission Electron Micrograph of NiAl-2-at\% Ta specimen deformed in Hot Compression at $1300^{\circ} \mathrm{K}$ to about $7 \%$ strain illustrating dislocation pinning at precipitation as a possible strengthening mechanism.

TABLE III. Grain Size Data for Binary NiAl (Micrometers)

\begin{tabular}{|c|c|c|c|c|c|c|}
\hline Composition & Annealing & & & Time & & \\
\hline & Temperature & 0 & 0.5 & 3.0 & 10.0 & 144.0 \\
\hline 48 at\% $\mathrm{Ni}$ & $1350^{\circ} \mathrm{C}$ & 3 & 12 & - & 13 & $=$ \\
\hline & $1450^{\circ} \mathrm{C}$ & 3 & 13 & 15 & 15 & 45 \\
\hline 50 at\% $\mathrm{Ni}$ & $1350^{\circ} \mathrm{C}$ & 2 & 15 & - & 19 & 28 \\
\hline & $1450^{\circ} \mathrm{C}$ & 2 & 17 & 20 & 20 & 48 \\
\hline 52 at\% $\mathrm{Ni}$ & $1350^{\circ} \mathrm{C}$ & 5 & 11 & - & 12 & 40 \\
\hline & $1450^{\circ} \mathrm{C}$ & 5 & 16 & 18 & 20 & 92 \\
\hline
\end{tabular}




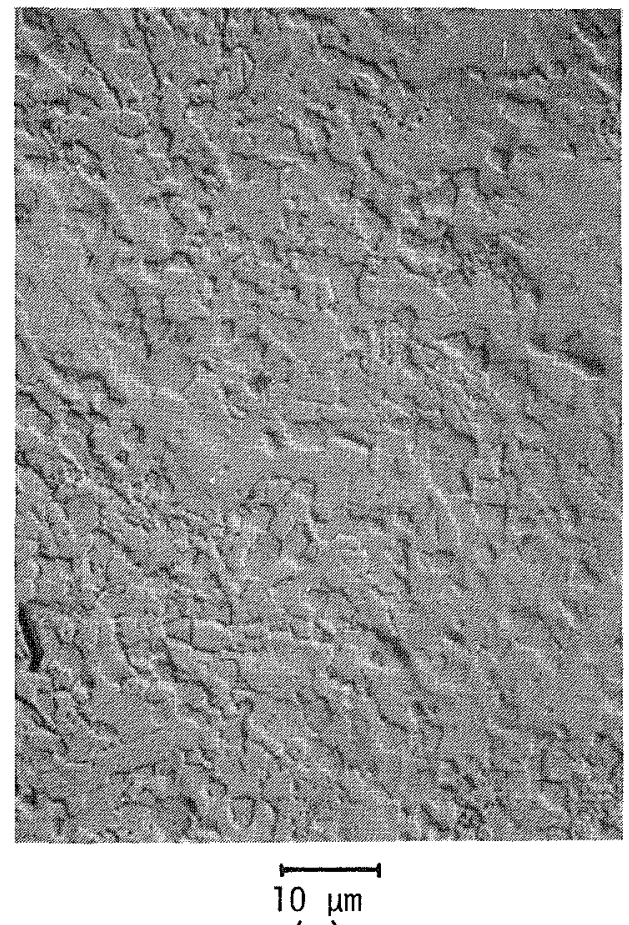

(a)

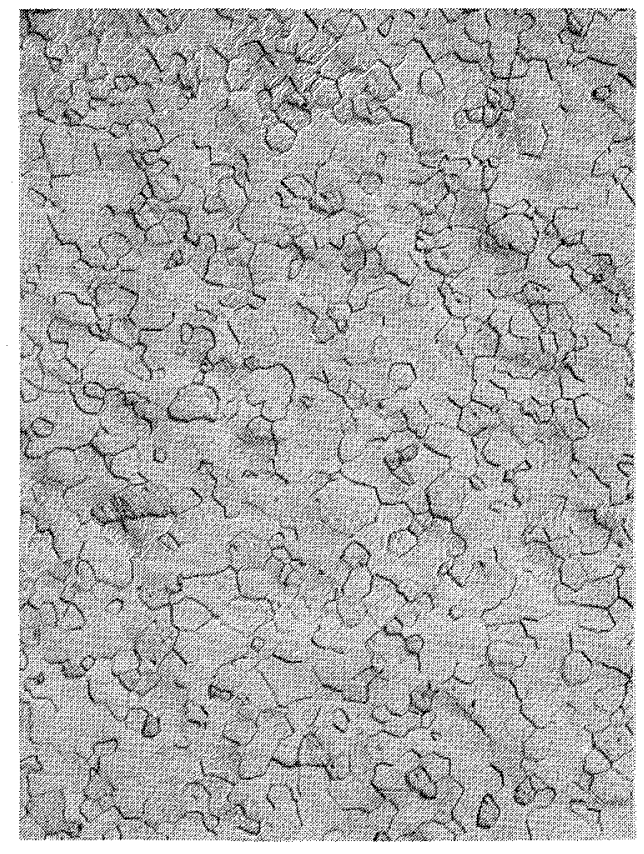

$2 \longdiv { 0 0 \mu \mathrm { m } }$

(b)

Fig. 6. Comparison of Optical Microstructure of the range of grain sizes of Binary Alloys used in this study. (a) As-Extruded Stoichiometric NiAl (1000X); (b) Stoichiometric NiAl annealed at $1723^{\circ} \mathrm{K}$ in argon for 144 hrs. (50X).

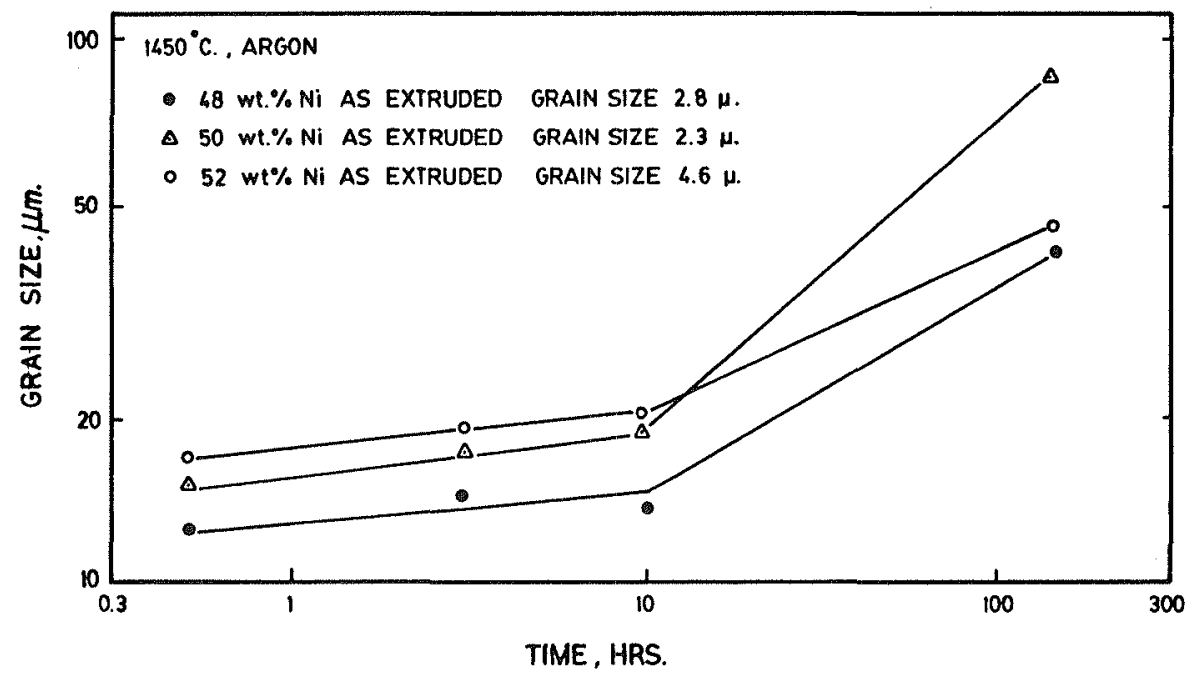

Fig. 7. Grain Growth Kinetics at $1723^{\circ} \mathrm{K}\left(1450^{\circ} \mathrm{C}\right)$ in Argon for Binary NiAl Alloys Prepared for this study. 
The hot compressive flow behavior of these alloys under slow strain rates exhibits some very unusual effects of grain size. Figure 8 compares the flow curves of the three compositions of binary $\mathrm{NiAl}$ at $1300^{\circ} \mathrm{K}$ and $3 \times 10^{-6} \mathrm{sec}^{-1}$. The fine grained (2um) stoichiometric alloy $(50 \mathrm{Ni})$ is twice as strong as the coarse grained (48 $\mu \mathrm{m})$ stoichiometric alloy. This is unusual since at high temperatures and slow strain rates metals normally do not exhibit grain boundary strengthening. The explanation for this behavior is not obvious although it seems to agree with some other results of this nature in ordered alloys $[6,7,8]$. Figure 9 is a typical TEM micrograph of the stoichiometric alloy and shows the presence of subgrain boundaries which are likely to play a key role in the explanation of the observed effects of grain size.

Strengthening due to grain boundaries is, however, observed to a very significant extent only in the stoichiometric alloy. The other alloys containing $48 \mathrm{Ni}$ and $52 \mathrm{Ni}$ do not exhibit the same magnitude of the effect, although the fine grained material is still slightly stronger. Once again, the explanation for this is not clear, although it must be related in some way to the effect of ordering on grain boundary structure and deformation mechanisms. A complication may be introduced by the possibility of grain boundary contamination during the annealing treatment in argon in view of the susceptibility of these alloys to grain boundary pest phenomenon [9].

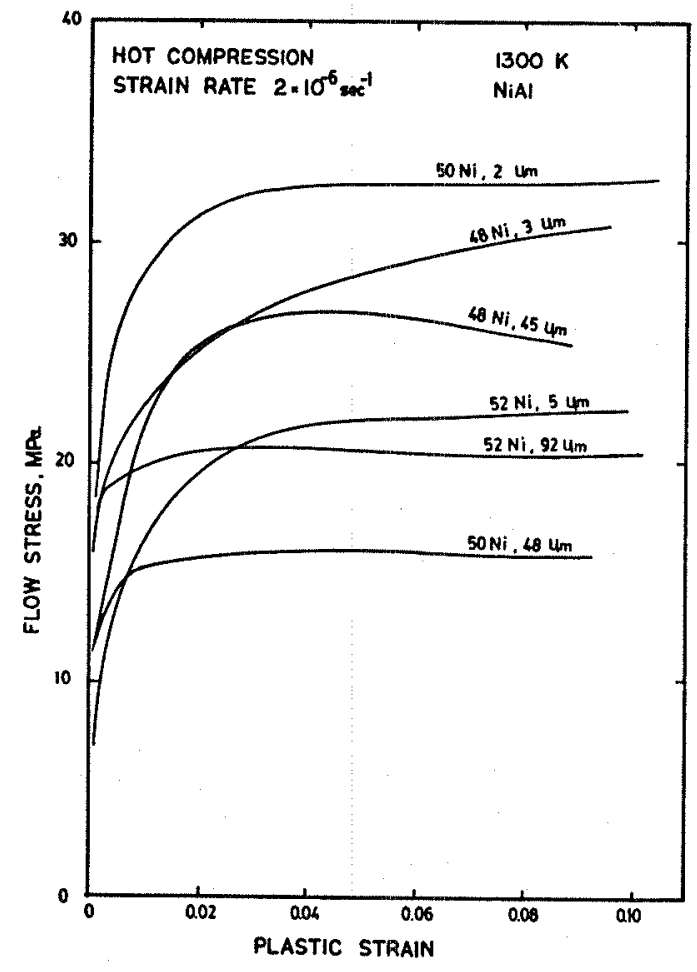

Fig. 8. Effect of Grain Size and Stoichiometry on Hot Compressive Flow Curves of Binary $\mathrm{NiAT}$ at $1300^{\circ} \mathrm{K}$.

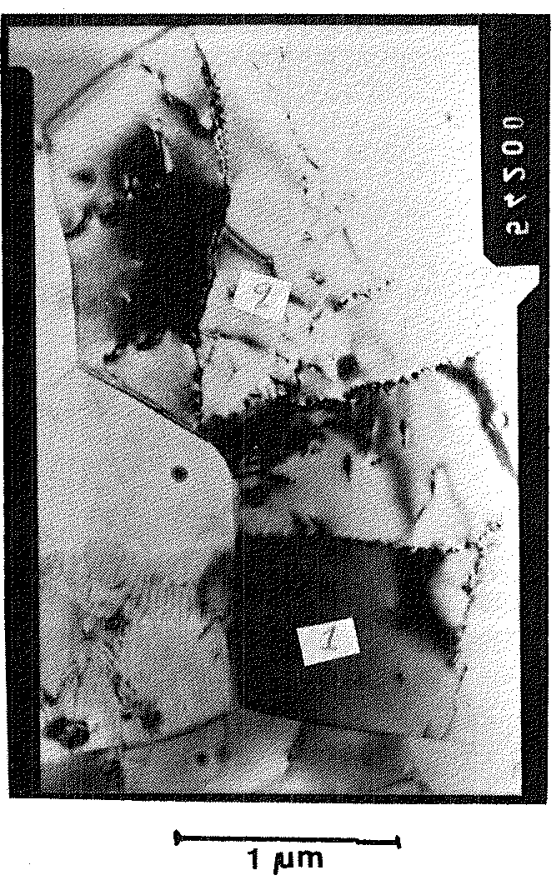

Fig. 9. Transmission Electron Micrograph of As-Extruded Binary Stoichiometric NiAl specimen illustrating the presence of Sub-qrain Boundaries. 
Some limited results at different temperatures presented in Figure 10 further illustrate the complexity of this behavior. The stoichiometric alioy which exhibits a large grain boundary strengthening effect at $1300^{\circ} \mathrm{K}$ does not exhibit such a dramatic effect of grain boundary strengthening at the lower temperature of $1100^{\circ} \mathrm{K}$, al though grain boundary strengthening should normally be expected to be more important at lower temperatures. The non-stoichiometric $52 \mathrm{Ni}$ alloy, however, appears to show the generally expected trend of grain boundary weakening at the higher temperature of $1400^{\circ} \mathrm{K}$.

These results illustrate the complex interactions between high temperature deformation, defect structures, ordering and grain size which need to be unraveled by carefully controlled studies.

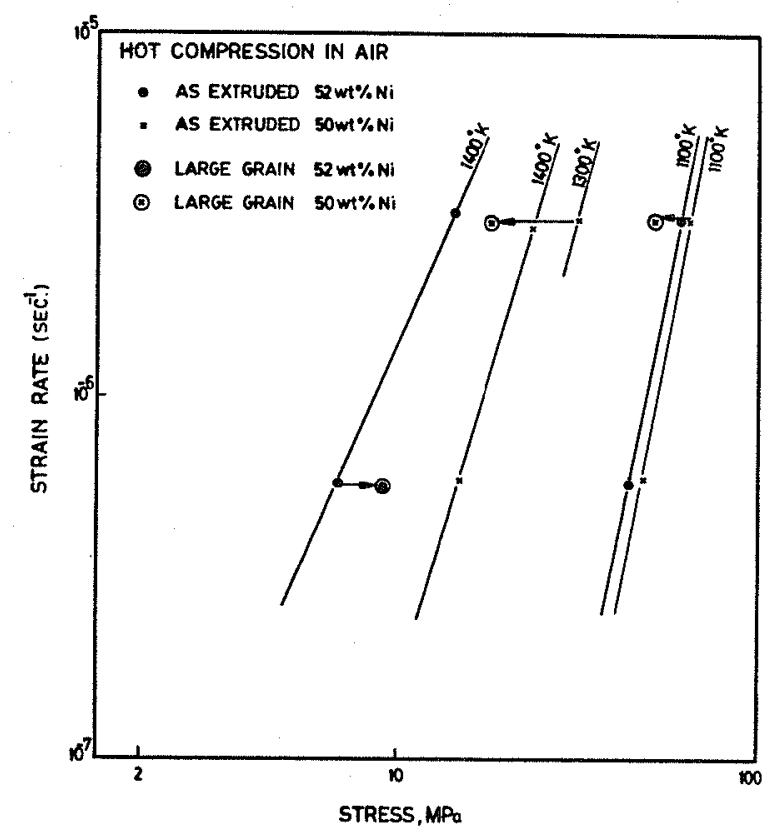

Fig. 10. Hot Compressive Flow Stress Behavior of Binary NiAl Alloys illustrating some of the interesting effects of temperature, grain size and stoichiometry.

\section{CONCLUSIONS}

The results presented in this paper show that a potentially useful strengthening mechanism for high temperature applications of NiAl alloys is by second phase strengthening. In particular, small additions of $\mathrm{Nb}, \mathrm{Ta}$ and $\mathrm{Hf}$ are found to exhibit this kind of strengthening to a significant extent. However, the mechanism of strengthening needs to be more clearly understood and optimized.

Some very interesting effects of grain size and stoichiometry have been observed, which need to be investigated more carefully before any explanations can be offered. In particular, the presence of grain boundary strengthening in the stoichiometric alloy even at fairly high temperatures is very unusual.

\section{ACKNOWLEDGEMENT}

The financial support of NASA Lewis Research Center is greatiy appreciated. 


\section{REFERENCES}

1. Hansen, Handbook of Binary Phase Diagrams.

2. V. M. Pathare, K. M. Vedula and R. H. Titran, to be published in Proceedings of the International Powder Metallurgical Conference, Toronto, June 1984.

3. A. J. Bradley and A. Taylor, Proc. Roy. Soc., 103, (1956), p. 54.

4. M. J. Cooper, Phil. Mag., 8, (1963), p. 805.

5. R. R. Vandervoort, A. K. Mukherjee and J. E. Dorn, Trans. Amer. Soc. Metals, 59, (1966), p. 930.

6. J. D. Whittenberger, Mat. Sci. and Engg., 57, (1983), p. 77.

7. E. M. Grala, "Mechanical Properties of Intermetallic Compounds", ed. J. H. Westbrook, John Wiley \& Sons, New York, 1960, p. 358.

8. E. P. Lautenschlager, D. A. Kiewit and J. 0. Brittain, Trans. Met. Soc. AIME, 233, (1965), p. 1297.

9. J. H. Westbrook and D. L. Wood, J. Inst. Metals, 91, (1962),p.174. 


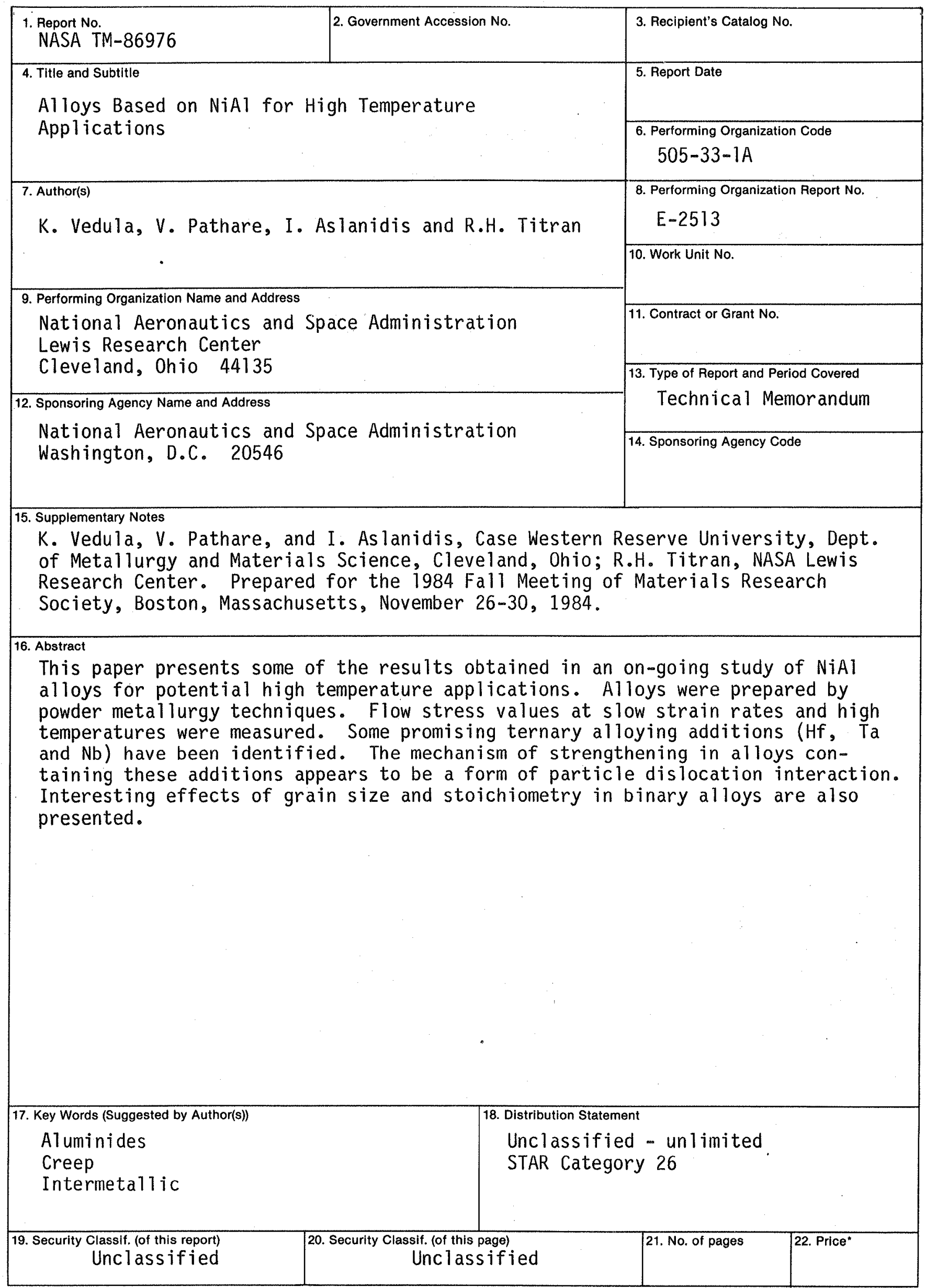

*For sale by the National Technical Information Service, Springfield, Virginia 22161 
End of Document 